\section{Title: An investigation into the origins and history of pandemic small ruminant} lentivirus infection.

\section{Running title: Emergence of pandemic lentivirus infection in small ruminants.}

Maria-Luisa Carrozza ${ }^{1^{*}}$, Anna-Maria Niewiadomska ${ }^{2^{*}}$, Maurizio Mazzei ${ }^{3}$, Mounir R. AbiSaid $^{4}$, Stéphane Hué ${ }^{5}$, Joshua B. Singer ${ }^{6}$, Joseph Hughes ${ }^{6}$, Robert J. Gifford ${ }^{6, \dagger}$

${ }^{1}$ Scuola Normale Superiore, Pisa, Italy; ${ }^{2}$ Aaron Diamond AIDS Research Centre, New York, USA; ${ }^{3}$ Department of Veterinary Science, Università of Pisa, Pisa, Italy; ${ }^{4}$ Faculty of Sciences II, Lebanese University, Al Fanar, Lebanon ${ }^{5}$ London School of Hygiene and Tropical Medicine, London, UK ${ }^{6}$ MRC-University of Glasgow Centre for Virus Research, Glasgow, UK

${ }^{*}$ Equal contributions

†To whom correspondence should be addressed: robert.gifford@glasgow.ac.uk 


\section{Abstract}

20 Small ruminant lentiviruses (SRLVs) cause chronic, persistent infections in 21 populations of domestic sheep and goats throughout the world. In this study, we use 22 genomic data to investigate the origins and history of the SRLV pandemic. To explore the 23 hypothesis that SRLV infection disseminated during Neolithic times, we performed a serology 24 and DNA sequencing-based investigation of SRLVs diversity in the Fertile Crescent region, 25 where domestication of sheep and goats is thought to have originally occurred. While we 26 found an elevated level of viral genetic diversity compared to other regions of the world, we 27 did not find unambiguous evidence that the Fertile Crescent region was the centre of the 28 contemporary SRLV pandemic. We therefore examined historical reports to investigate the 29 relationship between contemporary SRLV distribution and diversity and the emergence of 30 SRLV-associated disease. Historical data suggested that the emergence of SRLV31 associated disease might be associated with the long-distance export of exotic small 32 ruminant breeds - in particular, karakul sheep from Central Asia - during the late $19^{\text {th }}$ and 33 early $20^{\text {th }}$ centuries. Phylogeographic analysis could neither confirm nor refute this 34 hypothesis. However, we anticipate that future accumulation of genomic data from SRLV 35 strains found throughout the world may allow for a more definitive assessment. The openly 36 available data and resources assembled in this study will facilitate future investigations in this 37 area.

\section{Importance}

Viruses that cause chronic, persistent infections have circulated in animals for 41 millions of years. However, many have only emerged as pathogens within the far shorter 42 timeframe of recorded human history. It is important to understand the history of chronic viral 43 infections in domestic animals, so that more effective control and eradication programs can 44 be developed. 


\section{Introduction}

Small ruminant lentiviruses (SRLVs) are retroviruses that infect domestic sheep (Ovis aries) and goats (Capra hircus), causing chronic, persistent infections that ultimately lead to organ failure and death. Infection is usually only apparent following an incubation period of 3-4 years, and lifelong subclinical infections have been reported (1). General susceptibility and specific disease manifestations are influenced by genetic factors, and vary between species and breeds, but typically include pneumonia, wasting, paralysis, polyarthritis and mastitis.

The prototypic SRLV isolate was obtained from an epidemic that emerged in Icelandic sheep in the late 1930s. This isolate was cultivated in vitro in the late 1950s, and was named ovine maedi-visna virus (OMVV) (1-4). A virus closely related to OMVV was isolated from a North American dairy goat in 1974 and named caprine arthritis-encephalitis virus (CAEV) (5). It has subsequently become clear that each of these viruses occurs in both sheep and goats. Accordingly, they are now considered to represent two distinct genotypes (A and B respectively) within of a virus species (SRLV) (6). Analysis of complete viral genomes indicates that at least five major SRLV genotypes circulate in domesticated small ruminants (A, B, B3, C and E) (7-9). Genotypes A and B are widespread throughout the world $(6,7,10,11)$ having apparently been disseminated by recent livestock trade (6). By contrast, the divergent genotypes B3, C and E appear to have relatively restricted distributions. Phylogenetic studies have implicated livestock trade in pandemic spread of SRLV genotypes A and B (6). However, the early events that gave rise to pandemic SRLV spread are not well understood. In this study, we examined SRLV genome data using molecular phylogenetic approaches to investigate the origins and early history of the SRLV pandemic.

\section{Materials and methods}

\section{Serology and sequencing}

Serological testing of sheep and goat flocks in Lebanon was conducted during August 2012. Sampling took place in various regions of the 'Beqaa valley', a local center of agricultural production. Flocks were chosen at random from the Central, West and Eastern Beqaa, as well as the Northern region of Mount Lebanon. The small ruminant population in Lebanon consists mainly of local fat-tailed 'Awassi' breed sheep, whereas the goat population is $\sim 95 \%$ 'Baladi' and $\sim 5 \%$ 'Damascus'. Herds are often semi-nomadic, grazing during the day and returning to sheltered structures during the night, and frequently changing location depending on the season. Goats and sheep are often housed in the same areas and will graze together as one flock. Serological testing (ELISA) was conducted using plasma 
83

84

85

86

87

88

89

90

91

92

93

94

95

96

97

98

99

100

101

102

103

104

105

106

107

108

109

110

111

112

113

114

115

116

117

118

119

samples obtained from 449 animals: 221 goats and 228 sheep. A total of 36 goat, sheep and mixed flocks were sampled, with ten to fifteen animals in each flock being selected at random for plasma sampling. Of the initial 449 animals tested in Lebanon, 15.6\% (70 samples in 26 flocks: 20 goat; 50 sheep) were seropositive for exposure to SRLVs. Serotype was determined for a representative subset $(n=45)$ of positive samples using P16-25 ELISA. Whole blood was spun at 3500rpm, the serum and buffy coat collected, and stored at $-20 \mathrm{C}$ for further testing. ELISA assays were performed as described in (12). Net absorbance was obtained by subtracting the absorbance of negative antigen from the absorbance of each recombinant antigen. Cut-off value was defined as percentage of reactivity $20 \%$ of the absorbance of positive control included in each plate. Genomic DNA was extracted from stored white blood cells (buffy coats) using the DNeasy Blood and Tissue kit (QIAGEN), and quantitated using a nanodrop. Nested PCR was performed on the Gag region of the genome as described previously (13). PCR products were TA cloned into pCR4.0 sequencing vector (Life Technologies) and sent for sequence analysis (Genewiz). Viral sequences generated in this study have been submitted to GenBank under accession numbers KU170752KU170766.

\section{$\underline{\text { Dataset construction }}$}

Previously published SRLV sequences were retrieved from GenBank in 2015 using the following search phrases to query the 'Organism' field: 'Maedi Visna virus'; 'Ovine Progressive Pneumonia Virus'; 'Caprine Arthritis Encephalitis Virus'; 'Small Ruminant Lentivirus'; 'Ovine lentivirus'; 'Caprine lentivirus'. We filtered the 5,255 sequences recovered via this means to derive a subset of 585 previously published sequences that each represented a distinct infection. For each determined the pubmed ID of the study it was obtained in, the isolate name, the year of isolation, and the host species (sheep or goat). This information was obtained from GenBank files where possible, or else from scientific papers associated with the published sequences, and failing that via direct contact with study authors. Sequences in this dataset were aligned using a combination of MUSCLE (14) and Pal2Nal (15). We used GLUE - a data-centric bioinformatics framework for working with virus sequence data (16) - to capture the relationships between sequences, alignments and associated tabular data utilised in our investigation. The resultant resource is publicly available via GitHub (https://github.com/giffordlabcvr/SRLV-GLUE).

\section{Literature search/historical investigation}

To investigate previous reports of SRLV outbreaks, we conducted electronic searches for studies written in English, German, French, Portuguese, and that documented SRLV outbreaks based on either pathology, serology; by nucleic acid amplification. In 
120 November 2012, we searched the following databases: PubMed/Medline, JSTOR, Web of 121 Science, WorldCat and Google scholar. In addition searches were conducted for outbreaks

122 reported in ProMED Mail, as well as for sequences from unpublished studies reported in the

123 National Center for Biotechnology Information's nucleotide database. A non-redundant list of 124 reports was obtained using the following search terms; 'Maedi Visna Virus'; 'Visna'; 'Maedi'; 125 'Ovine Progressive Pneumonia Virus'; 'Caprine Arthritis Encephalitis Virus'; 'MVV'; 'CAEV'; 126 'SRLV'; 'Small Ruminant Lentiviruses'; 'Montana Sheep Disease'; 'Montana Progressive 127 Pneumonia'; 'Chronic Progressive Pneumonia'; 'Zwoegerziekte'.

\section{Phylogenetic, phylogeographic and phylodynamic analysis}

130 Phylogenetic analysis of SRLV gag sequences obtained from sheep in Lebanon and of complete SRLV genome sequences was performed using RaXML (17), using the general time reversible (GTR) nucleotide substitution model and 1000 bootstrap replicates. Timecalibrated phylogenies were reconstructed using BEAST 1.8.2 with the SDR06 substitution model and an uncorrelated lognormal relaxed clock model. Molecular clock model comparison was investigated using AICM available in Tracer. In all cases the model comparison indicated support for the relaxed clock. Additionally, the posterior distribution for the coefficient of variation in the uncorrelated lognormal relaxed clock model did not impinge on zero indicating that the relaxed clock model provides a better fit to the data than the strict clock. After testing for the best molecular clock model, we tested two different coalescent models: Bayesian skyline plot and Bayesian skyride. Trees were annotated using FigTree (http://tree.bio.ed.ac.uk).

The dispersal between countries was estimated using the discrete state

143 phylogeographic approach described in Lemey et al. (18) using a symmetric substitution 144 model and implementing the Bayesian stochastic search variable selection model (BSSVS).

145 The Bayesian GMRF skyride coalescent model was selected as a flexible demographic tree 146 prior. Stationarity was assessed on the basis of the effective sampling size (ESS) after a $14710 \%$ burning using Tracer and two independent runs were generated to confirm 148 convergence. The two independent runs were combined using LogCombiner and 149 summarized with TreeAnnotator. In cases where there was a large amount of uncertainty in 150 the node heights resulting in negative branch length, the common ancestor tree was used to 151 summarise the trees instead of the Maximal Clade Credibility topology. Whole genome 152 analysis did not produce ESS values above 100 for the root height and a number of other 153 parameters for SRLV-A and SRLV-B probably due to insufficient data. 


\section{Results}

\section{SRLV diversity in the Fertile Crescent region}

158 Archaeological and genetic evidence indicate that both sheep and goats were 159 domesticated in the 'Fertile Crescent' region of Western Asia 10.5-11 thousand years ago

160 (19) (Figure 1a). The presence of highly divergent SRLV genotypes in remnant populations 161 of primitive small ruminant breeds (genotype C in Norway, genotype E in Sardinia) is 162 consistent with an ancestral radiation of SRLV genotypes out of the Fertile Crescent region in 163 association with the diffusion of early agricultural systems during the early Neolithic $(20,21)$. 164 However, this pattern might also be accounted for in other ways (e.g. each genotype might represent an independent introduction of virus into the domesticated small ruminant population from a wild ruminant species).

We carried out a study of SRLV diversity in the Fertile Crescent region to investigate whether this area might have been the centre of an ancient SRLV radiation. We focused on Lebanon, a country in the Levant region, where (Figure 1b), where some of the earliest human civilizations are believed to have developed (22). Serological testing of 886 animals indicated that diverse SRLVs are present in both countries (Table 1). Furthermore, overall prevalence was relatively high ( 21\%) in comparison with previous global surveys (23), but similar to estimates obtained in other countries in the region $(13,24)$. We used PCR to obtain gag gene amplicons from a randomly selected subset of our SRLV-positive samples (primers are listed in Table S1).

We obtained amplicons from fifteen samples and investigated their evolutionary relationships to a representative set of published sequences (Figure 2). In phylogenies constructed using this dataset, three distinct clades of Levantine isolates (Lev I-III) were observed. The Lev-I and Lev II clades grouped robustly within the diversity of previously characterized SRLV-A isolates, while Lev-III was relatively distinct from all previously sampled SRLV genotypes. A full-length proviral genome sequence has previously been recovered for one Lev-III isolate sampled in Jordan (Jord1). We used full-length genome sequences to reconstruct the phylogenetic relationships between Jord1 and other SRLV genomes, showing it is approximately as distantly related to established SRLV genotypes as they are to one another (Figure S1).

While the Lev III clade is highly divergent, it does not represent an obvious ancestor to all other SRLV genotypes. Furthermore, although the overall level of diversity in the Fertile Crescent region appears to be relatively high, based on observations from our study and others (10), the range of genotypes and novel lineages identified was not as exceptionally

190 high as might be expected if this region were the centre of an ancient SRLV radiation (i.e. 191 similar to the high diversity of human immunodeficiency virus type 1 (HIV-1) found in areas of 192 West Central Africa). In fact, most of the isolates detected in our study grouped within the 
193 diversity of pandemic SRLV-A strains found in Europe and North America, indicating they are

194 as likely to have been imported into the region as exported from it (Figure 2).

195

Recorded history of pandemic SRLV emergence and spread

Previous epidemiological studies have indicated that pandemic spread of SRLVs may only have occurred relatively recently $(6,23,25,26)$. They do not appear to have spread in parallel with the first European colonists, as seems to be the case for many other livestock pathogens $(27,28)$. For example, SRLV-A has never been reported in Australia or New Zealand, where sheep are largely descended from animals imported in the 19th century from the UK, Germany, South Africa and North America $(6,25)$. This suggests that SRLVs were not widespread during the 'Age of Discovery' (from 1500 to 1700), when the first exports of small ruminants from Europe to Africa, Oceania and the Americas took place.

To explore the manner in which SRLVs emerged as globally distributed pathogens, we reviewed the historical evidence for SRLV-associated disease in countries throughout the world. For each country where SRLV infection has been reported, we determined the earliest reliable evidence for the presence of the virus (Table S1, Table S2). Previous studies have identified diseases reported in the past that appear likely - in retrospect - to have been caused by SRLVS (1). Cases where the only available evidence for historical SRLV infection

211 is based on a description of disease pathology have to be viewed cautiously, particularly 212 because of potential confusion with sheep pulmonary adenomatosis, caused by Jaagsiekte 213 sheep retrovirus (JSRV). Nonetheless, SRLV-A can confidently be stated to have been 214 present in Europe since at least 1933, because the Icelandic epidemic from which the 215 prototypic SRLV-A strain was derived was definitively traced to an importation of Karakul 216 sheep in this year (29).

217 Intriguingly, the early emergence of SRLV-A infection closely mirrors the early $20^{\text {th }}$ 218 century diffusion of Karakul, which are among the oldest domesticated sheep breeds $(30,31)$ 219 (Figure 3). The breed is native to Central Asia, and arrived in Iceland via the Institute for 220 Animal Breeding, in Halle, Germany. Karakul sheep were originally exported to Halle from 221 Bukhara in Uzbekistan in 1903 (32), and were also introduced to the United States in the 222 same decade (33) (Table S1). In the first half of the $20^{\text {th }}$ century, a cluster of similar disease 223 syndromes emerged, all of which are now considered likely to have been caused by SRLV 224 infection (29). 'Graaf-Reinet disease' was first described in South Africa in 1915, less than a 225 decade after the introduction of Karakul into the region. The same year, 'Montana sheep disease' was reported for the first time in the United States, seven years after the arrival of 227 Karakul. In Europe, both maedi-visna (in Iceland), and 'la bouhite' (in France) emerged in $228 \sim 1930-50$, in parallel with the initial dissemination of German Karakul in Europe. 

was conspicuously associated with Swiss dairy goat breeds, particularly the Swiss Saanen breed (Table S2). Many of the first reported outbreaks of SRLV infection in goats involved this popular breed (34). Indeed, the prototypic SRLV-B isolate (CAEV Cork) derives from an outbreak of chronic, progressive disease that emerged in a North American population of Saanen goats in 1970 (35). Until the late $19^{\text {th }}$ century, small ruminant breeds such as Saanen and Karakul had strictly defined geographic distributions. A role for the livestock trade in SRLV emergence has been proposed previously. However, the role of specific breed movements in driving the early emergence of pandemic strains has not been closely examined.

239

\section{Phylogeographic investigation of pandemic SRLV spread}

We used Bayesian phylogeographic approaches to investigate whether available genomic data supported a role for breed dispersal in the emergence of pandemic SRLV infection, as suggested by our investigation of historical records. We compiled a comprehensive set of published SRLV sequences. From an initial set of 5,255 sequences, we derived a subset of 697 that together represented 585 unique field isolates, each obtained from a distinct infected animal (Table 2, Table S3). We added the fifteen SRLV gag sequences we obtained in Lebanon to this set. Together, this set of sequences represented 600 isolates sampled in a total of 30 countries, with dates of sampling ranging from 1949 to 2013. A preliminary phylogenetic analysis (data not shown) was performed to determine the genotype of all sequences in this set. We then created individual multiple sequence alignments (MSA) for each of the pandemic SRLV strains (SRLV-A and SRLV-B1). From these alignments, we derived a total of eight alignment partitions (Table S4) - two within the group-specific antigen (gag) gene, and two partitions within the polymerase ( $p o l)$ gene. We detected temporal structure in five of the eight datasets, despite the presence of outliers (Table S5). The results of Bayesian phylogeographic analysis of the four pol partitions are shown in Figure 4 (SRLV-A) and Figure 5 for (SRLV-B1), while the results obtained for the four gag partitions are shown in Figure S2 (SRLV-A) and Figure S3 for (SRLV-B1). Table 4 and Table 5 provide information about specific nodes of interest in all eight phylogenies. We obtained more robust results when using pol, however, we have included the results obtained for gag as these provide some potentially useful insights regarding the epidemic in specific parts of the world.

In general, phylogenies were only moderately structured as opposed to 'star-like'. We obtained robust support for nodes near the phylogeny tips, particularly within clades of 
266

267

268

269

270

271

272

273

274

275

276

277

278

279

280

281

282

283

284

285

286

287

288

289

290

291

292

293

294

295

296

297

298

299

300

301

geographic regions) had high support. For all four pol partitions, and one SRLV-B1 gag partition, the location of the most recent common ancestor was placed in Switzerland. Ancestral locations within Asia Minor were obtained for SRLV-A gag partitions, but with low support. One SRLV-B1 gag partition placed the most recent common ancestor in the United States (US), with moderately high support.

Overall, the results of Bayesian analysis were consistent with a scenario within which both SRLV-A and SRLV-B1 disseminated worldwide from a European epicentre. Where we were able to confidently estimate the location of deeper nodes in the phylogeny, we found these were placed in Central Europe. By contrast, clades sampled in Asia, South America and the around the Northern and Western periphery of Europe (i.e. Ireland, Norway, Finland) were observed to have relatively recent common ancestors (Table 4, Table 5).

Although the lack of resolution in our phylogenies (as well as the limitations of opportunistic sampling) prevented us from inferring the precisely the direction and timing of global SRLV spread, we were able to confidently estimate tMRCAs for most of the MSAs examined. For SRLV-A, we obtained IMRCA estimates in the late $19^{\text {th }}$ century - shortly predating the first Karakul exports from Central Asia - for both reverse transcriptase (RT) (1883, 1820-1923 95\%HPD) and integrase (IN) (1887, 1837-1915 95\%HPD). The SRLV-A gag partitions yielded more conflicting results: for the matrix partition (Gag MSA 1) we obtained much older estimates with wide error margins, whereas the capsid partition (Gag MSA 2) yielded a somewhat more recent IMRCA (Table 3). For SRLV-B1 the capsid partition yielded unreliable tMRCA estimates with wide error margins. However, we obtained more reliable and generally consistent results from the other three MSA partitions, which provided tMRCA estimates of 1966 for RT (1958-1974 95\%HPD), 1952 for IN (1939-1964 95\%HPD), and 1972 for matrix (1957-1974 95 HPD) (Table 4).

\section{Discussion}

In this study, we used molecular phylogenetic approaches to investigate the origins and history of pandemic SRLV spread. To investigate the hypothesis that SRLV originally disseminated out of Western Asia during the early Neolithic period (i.e. in association with domesticated small ruminants) we sampled SRLV strains circulating in the Fertile Crescent region where domestication of these species is thought to have occurred. We found a relatively high prevalence and diversity of SRLV strains, but we did not find obvious evidence of the region having been the centre of an ancient SRLV radiation. The lack of clear evidence that the various SRLV genotypes derive directly from a virus population that circulated in the ancestral small ruminant populations from which modern breeds are derived, does not rule out the possibility that they did. It could be that our sampling was not entirely representative, 
302 or that SRLV diversity in the region has been greatly influenced in recent times by factors 303 such transport and migration (6).

304 To investigate the origins and timing of pandemic SRLV spread, we combined a 305 review of historical records with a phylogenetic investigation of SRLV genome data. Our 306 research led us to consider the possibility that the emergence of pandemic SRLV infection 307 might have its roots in the late $19^{\text {th }}$ and early $20^{\text {th }}$ century, during which time 'exotic' small ruminant breeds were exported to Europe, North America and Africa. In particular, we noted that historical reports suggest the early pattern of emergence of SRLV-associated disease around the world appears - at least superficially - to be correlated with the export of karakul - a breed of fat-tailed sheep, native to Central Asia (Figure 3). Even though it was established relatively early on that SRLV-A infection was imported to Iceland along with a flock of karakul sheep in the 1930s, this breed has not previously been implicated in global spread of SRLV. However, a role for karakul in the early emergence of SRLV-A might easily have been missed if the SRLV strains exported along with this breed were not associated with obvious disease in their natural host. Current evidence indicates that Lentiviruses, including some SRLVs, are relatively apathogenic in populations with which they have longer-term associations $(36,37)$. Thus, in the light of what we now know lentivirus pathology and its relationship to host genetic variation, a plausible hypothesis accounting for the emergence of pandemic SRLV-associated disease is that it was driven by the introduction (via karakul export) of Central Asian SRLV strains into populations of small ruminants in Europe, Africa and America that had previously only been exposed to SRLV strains prevalent in Europe.

We propose that the early spread of SRLVs could have been enabled by the creation of new contact networks in livestock populations, leading to particular small ruminant breeds and populations being brought into contact for the first time. Subsequent to this, the development of international livestock trade (6) - as well as the development and uptake of new systems of agriculture - would presumably have helped facilitate the further spread of SRLVs from European and Asian epicenters to Africa, the Americas, Oceania, and East Asia. The capacity of some small ruminant breeds to harbor SRLV infection without exhibiting symptoms, and a lack of understanding about the nature of slow virus infections prior to the 1950s (29), would presumably helped enable this relatively recent wave of global SRLV spread.

To investigate whether available genomic data supported this hypothesis, we performed a phylogeographic analysis of the available sequence data for the pandemic SRLV strains A and B1. Overall, results were consistent with both strains having spread worldwide relatively recently (i.e. within the $20^{\text {th }}$ century), emerging from a Eurasian source. 
339 first Karakul exports from Central Asia - and thus consistent with a scenario under which 340 these exports ultimately led to the emergence of an SRLV pandemic.

341 SRLV-B1 appears to have disseminated globally more recently than SRLV-A, from an 342 unknown source in Europe. Global spread of this SRLV lineage is conspicuously associated 343 with Swiss dairy goat breeds in general, and the Saanen breed in particular (Table S2).

344 Many of the first reported outbreaks of SRLV infection in goats involved this breed, which 345 was first exported from Switzerland in the late $19^{\text {th }}$ century, and has subsequently been 346 introduced to many countries throughout the world (34). However, given that (i) SRLV 347 infection is known to cause disease in Saanen and other Swiss dairy goat breeds, and; (ii) 348 these breeds have been exported from Switzerland since the late $19^{\text {th }}$ century (34), It seems 349 unlikely that Swiss dairy goats are the ancestral hosts of SRLV-B1. One possibility is that 350 spread of B1 from a Swiss epicenter was preceded by the introduction of novel SRLV 351 diversity into the Swiss small ruminant population during the early $20^{\text {th }}$ century.

A major limitation of our analysis is that the majority of sequence data we examined was opportunistically sampled from what was already available in GenBank. Sampling of SRLV diversity so far has been patchy, and in addition, most of the available sequences are sub-genomic (see Table 2), which limits what can be inferred. Furthermore, sampling is heavily biased toward certain areas, distorting our phylogeographic inference. For example, Switzerland was probably the most thoroughly sampled country in our dataset, thus the phylogeographic placement of the SRLV-A and SRLV-B MRCAs in Switzerland has to be viewed with some caution. Interestingly, however, Karakul are documented as having been present in Switzerland since at least the early 1930s (38).

Test and removal programs are currently used as a means of controlling SRLV 362 infection, with varying levels of effectiveness (39). In fact, recent years have seen the 363 emergence of SRLV infection in countries where it had not previously been documented, as well as the re-emergence of disease in areas where it had been considered to be under control $(40,41)$. We therefore anticipate that the use of genome data to investigate SRLV breakdowns will increase in future. The increased availability of genome sequences from SRLV strains found throughout the world - particularly in Central Asia - should eventually allow for a more definitive assessment of the hypothesis presented here, and provide a clear picture of the pattern of pandemic SRLV spread. The more ancient spread of SRLV viruses, which is proposed to date back to the Neolithic, is unlikely to be amenable to phylogeographic analysis due to the time-dependence of viral evolutionary rates (42).

372 However, the overall distribution of SRLV strains in Europe and Asia (particularly Central 373 Asia) may well be revealing in this respect. The resources assembled in this study will not 374 only facilitate further investigation of historical SRLV spread, but can also provide a 375 foundation for the development of SRLV surveillance systems that utilise genomic data. 
bioRxiv preprint doi: https://doi. org/10.1101/236117; this version posted May 30,2018 . The copyright holder for this preprint (which was not certified by peer review) is the author/funder, who has granted bioRxiv a license to display the preprint in perpetuity. It is made available under aCC-BY-NC-ND 4.0 International license.

376 Table 1. ELISA results from small ruminants in Jordan and Lebanon

\begin{tabular}{|c|c|c|c|c|c|c|}
\hline \multirow[t]{2}{*}{ Species (Breed) } & \multirow[t]{2}{*}{ Sample number } & \multicolumn{2}{|c|}{ Positive samples } & \multicolumn{3}{|c|}{ Serotype reactivity } \\
\hline & & $\#$ & $\%$ & A & B & $\mathbf{E}$ \\
\hline Sheep (Awassi) & 457 & 131 & 28.7 & 23 & 20 & 9 \\
\hline Sheep (Australian) & 5 & 3 & 60.0 & 2 & - & 1 \\
\hline Goat (Baladi) & 408 & 48 & 11.8 & 11 & 24 & 4 \\
\hline Goat (Damascus) & 14 & 4 & 29.0 & 1 & 1 & 1 \\
\hline Goat (Baladi x Damascus) & 2 & 0 & 0.00 & - & - & - \\
\hline Totals & 886 & 186 & 21 & 37 & 45 & 15 \\
\hline
\end{tabular}

Legend: SRLV prevalence and genotypes in Jordan and Lebanon. ELISA assays were performed on sera collected from sheep and goats belonging mostly to local breeds. The serotype reactivity of a subset of sera comprising 45 Lebanese and 112 Jordanian samples was analysed with a genotyping ELISA assay targeted against the p16/matrix (MA) and p25/capsid (CA) proteins of $A, B$ and $E$ genotype.

383 
bioRxiv preprint doi: https://doi.org/10.1101/236117; this version posted May 30, 2018. The copyright holder for this preprint (which was not certified by peer review) is the author/funder, who has granted bioRxiv a license to display the preprint in perpetuity. It is made available under aCC-BY-NC-ND 4.0 International license.

\begin{tabular}{llllllll}
$(6)$ & AY454233-296 & Ch, Oa & 1999 & Pol & CH & 64 & 64 \\
$(6)$ & AY445885 (G4668) & Ch & 1999 & Genome & CH & 1 & 1 \\
$(7)$ & AY577031-3 & Ch, Oa & 2003 & Gag-pol & CH & 3 & 3 \\
$(7)$ & AY577034-9 & Ch, Oa & 2003 & Gag & CH & 6 & 6 \\
$(74)$ & AY530289-93 & Ch, Oa & 2002 & Gag & GR & 5 & 5 \\
$(75)^{*}$ & HM449450 & Ch & 2007 & Env & IT & 1 & 234 \\
$(76)^{*}$ & EF685749, 83 & Ch & 2006 & Env & IT & 2 & 194 \\
$(11)$ & See legend & Ch, Oa & $2009-10$ & Gag-pol & IT & 55 & 61 \\
$(77)^{*}$ & EF144472, 82, 93, 94 & Ch & 2006 & Env & IT & 4 & 45 \\
$(37)$ & EU293537 (Roccaverano) & Ch & 2008 & Genome & IT & 1 & 1 \\
$(37)$ & EU726488-525 & Ch & $1999,06,07$ & Gag & IT & 38 & 38 \\
$(8)$ & EF676000-26 & Ch, Oa & 2006 & Gag & IT & 24 & 24 \\
$(8)$ & EU010120-6 & Ch & 2006 & Gag & IT & 7 & 7 \\
$(78)$ & DQ013214-43 & Ch, Oa & 2005 & Pol & IT & 30 & 30 \\
$(79)$ & AY044803-10 & Ch & 1991 & Gag & IT & 8 & 8 \\
$(80)$ & GQ381130 (Seui) & Ch & 2003 & Genome & IT & 1 & 1 \\
$(80)$ & GQ428519-36 & Ch & $2008-09$ & Gag & IT & 18 & 18 \\
$(10)$ & JF502416 (Fonni) & Oa & 2003 & Genome & IT & 1 & 1 \\
$(10)$ & JF502417 (Volterra) & Oa & 2004 & Genome & IT & 1 & 1 \\
$(10)$ & JF520393-406 & Ch, Oa & $2008-09$ & Gag & IT & 5 & 5 \\
$(81)$ & EU709743, EU702487 & Oa & 1991 & Env & IT & 2 & 3 \\
$(82)$ & FJ623120-25 & Ch, Oa & 2008 & Gag & PL & 6 & 6 \\
$(82)$ & FJ623110-19 & Ch, Oa & 2008 & Env & PL & 10 & 10 \\
$D S$ & JN084103 & Ch & 2008 & Gag & RU & 1 & 1 \\
DS & JN008914 & Ch & 2008 & Env & RU & 1 & 1 \\
$(83)$ & JQ610956-JQ611030 & Oa & 2011 & Pol & SL & 75 & 75 \\
$(83)$ & JX469600-10 & Ch, Oa & $2008-11$ & Gag-pol & SL & 11 & 11 \\
& & & & Total & $\underline{\mathbf{4 5 3}}$ \\
\hline
\end{tabular}

Legend. Previously sequenced SRLV isolates, grouped by study. ${ }^{a} D S=$ direct submission to GenBank. Asterisks indicate studies of intra-host diversity from which a subset of sequences (one per animal) was selected. ${ }^{b}$ Accession numbers are shown only for sequences included in the reference set. For complete genome sequences the isolate name is shown in bold and in parenthesis. $N A=$ not applicable ${ }^{\mathrm{c}} \mathrm{Oa}=$ Ovis aires; $\mathrm{Ch}=$ Capra hircus. ${ }^{\mathrm{d}}$ Year of collection is shown where it could be ascertained, $N K=$ not known. ${ }^{\text {e }}$ Only sequences that encoded $>500$ base pairs of gag, pol,; env were included in the reference set ${ }^{f}$ ISO country code (state). ${ }^{g}$ Reference set was restricted to one sequence per infected animal (number shown as 'in set'). Where multiple sequences were available the total is indicated under 'in study'. Accession numbers not listed in the table are as follows; Thai sequences (GQ161209-15, JF714253-5, EU983108-9, EU919141, FJ167525)); North American sequences from reference (49) (GQ255391, GQ255386, GQ255401, GQ255411, GQ255385, GQ255403, GQ255417, GQ255423, GQ255428, GQ255433); North American sequences from reference (50) (AY362022, AY362024, AY362026, AY362029, AY362030, AY362032, AY362035, AY362038); Italian sequences from reference (11) (FR687200, FR693808-32, FR694686-96, FR694908-21, FR695719, FR828809-16.

402 
Table 3. tMRCAs of selected clades within SRLV-A

\begin{tabular}{|c|c|c|c|c|c|c|c|c|}
\hline Partition ${ }^{a}$ & Node \# ${ }^{\mathrm{b}}$ & Clade description ${ }^{c}$ & Posterior $^{a}$ & $\operatorname{Region}(\mathbf{s})^{e}$ & Location ${ }^{\prime}$ & p.loc ${ }^{g}$ & Age & 95\% HPD \\
\hline Gag MSA 1 & 1 & Polish & 0.55 & C. Europe & Poland & 0.86 & 1884 & $54-296$ \\
\hline Gag MSA 1 & 2 & US & 0.98 & N. America & USA & 0.93 & 1891 & $56-272$ \\
\hline Gag MSA 1 & 3 & PL-US-JP-IT-IS & 0.94 & Global & South Africa & 0.16 & 1798 & $105-509$ \\
\hline Gag MSA 1 & 4 & Finnish & 1.00 & N. Europe & Finland & 1.00 & 1970 & $24-72$ \\
\hline Gag MSA 1 & 5 & Spanish & 1.00 & W. Europe & Spanish & 1.00 & 1858 & $63-361$ \\
\hline Gag MSA 1 & 6 & Root & 1.00 & Global & Jordan & 0.12 & 1760 & $112-596$ \\
\hline Gag MSA 2 & 1 & Italy & 0.95 & S. Europe & Italy & 0.93 & 1959 & $9-18$ \\
\hline Gag MSA 2 & 2 & Greece & 0.96 & S. Europe & Greece & 0.98 & 1975 & $24-51$ \\
\hline Gag MSA 2 & 3 & Jordan-Lebanon-Turkey & 0.98 & Asia Minor & Turkey & 0.68 & 1972 & $24-56$ \\
\hline Gag MSA 2 & 4 & S Europe-Asia Minor & 0.77 & S. Europe-Asia Minor & Turkey & 0.55 & 1951 & $43-81$ \\
\hline Gag MSA 2 & 5 & Lev-II & 1.00 & Asia Minor & Lebanon & 0.99 & 1990 & $10-34$ \\
\hline Gag MSA 2 & 6 & US-CA & 1.00 & N. America & USA & 0.64 & 1978 & $24-48$ \\
\hline Gag MSA 2 & 7 & Swiss & 0.99 & C. Europe & Switzerland & 0.97 & 1976 & $25-48$ \\
\hline Gag MSA 2 & 8 & Turkish & 0.96 & Asia Minor & Turkey & 0.96 & 1968 & $25-61$ \\
\hline Gag MSA 2 & 9 & ES-UK & 0.99 & W. Europe & Spain & 0.47 & 1978 & $30-40$ \\
\hline Gag MSA 2 & 10 & US-CA & 0.99 & N. America & USA & 0.66 & 1964 & $35-61$ \\
\hline Gag MSA 2 & 11 & US-CA-FI-ES & 0.76 & Europe-N. America & Turkey & 0.53 & 1942 & $50-88$ \\
\hline Gag MSA 2 & 12 & Finland & 1.00 & N. Europe & Finland & 1.00 & 1987 & $21-29$ \\
\hline Gag MSA 2 & 13 & Finnish-BR & 0.95 & N. Europe & Finland & 0.29 & 1955 & $38-75$ \\
\hline Gag MSA 2 & 14 & Swiss & 1.00 & C. Europe & Switzerland & 1.00 & 1985 & $22-34$ \\
\hline Gag MSA 2 & 15 & ES & 1.00 & W. Europe & Spain & 0.99 & 1958 & $38-70$ \\
\hline Gag MSA 2 & 16 & Root & 1.00 & Asia Minor & Turkey & 0.38 & 1930 & $67-100$ \\
\hline Pol MSA 1 & 1 & Swiss & 1.00 & C. Europe & Switzerland & 0.99 & 1977 & $24-49$ \\
\hline Pol MSA 1 & 2 & Swiss-Spanish-Slovenian & 0.76 & C. Europe & Switzerland & 0.80 & 1911 & $63-157$ \\
\hline Pol MSA 1 & 3 & Swiss-US & 0.99 & C. Europe & Switzerland & 0.75 & 1916 & $58-148$ \\
\hline Pol MSA 1 & 4 & Irish & 1.00 & W. Europe & Ireland & 0.99 & 1993 & $14-24$ \\
\hline Pol MSA 1 & 5 & Irish-ZA & 0.94 & Europe-Africa & South Africa & 0.28 & 1932 & $51-117$ \\
\hline Pol MSA 1 & 6 & Irish-ZA-UK-SL & 0.91 & C. Europe & Switzerland & 0.38 & 1918 & $60-139$ \\
\hline Pol MSA 1 & 7 & Norwegian & 1.00 & C. Europe & Norway & 0.99 & 1984 & $15-43$ \\
\hline Pol MSA 1 & 8 & Norway-Swiss & 0.76 & C. Europe & Switzerland & 0.61 & 1920 & $54-139$ \\
\hline Pol MSA 1 & 9 & Norway-Iceland-Portugal & 0.93 & Europe & Switzerland & 0.34 & 1920 & $77-155$ \\
\hline Pol MSA 1 & 10 & Root & 1.00 & C. Europe & Switzerland & 0.60 & 1883 & $88-191$ \\
\hline Pol MSA 2 & 1 & Slovenian & 1.00 & C. Europe & Slovenia & 1.00 & 2003 & $9-15$ \\
\hline Pol MSA 2 & 2 & Slovenia-UK & 0.98 & C. Europe & Slovenia & 0.43 & 1927 & $54-113$ \\
\hline Pol MSA 2 & 3 & Slovenia-UK-IS-ZA & 0.91 & C. Europe & Switzerland & 0.72 & 1905 & 84-159 \\
\hline Pol MSA 2 & 4 & Swiss & 1.00 & C. Europe & Switzerland & 0.87 & 1926 & $55-116$ \\
\hline Pol MSA 2 & 5 & ES & 1.00 & W. Europe & Spain & 0.98 & 1951 & $32-86$ \\
\hline Pol MSA 2 & 6 & Swiss-ES-US-SL & 1.00 & C. Europe & Switzerland & 0.83 & 1907 & $70-137$ \\
\hline Pol MSA 2 & 7 & Root & 1.00 & C. Europe & Switzerland & 0.76 & 1875 & $97-174$ \\
\hline
\end{tabular}

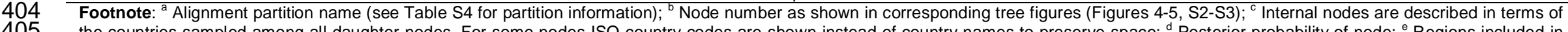

406 daughter nodes; ${ }^{\dagger}$ Estimated country location of node; ${ }^{9}$ Posterior probability of location. 
Table 4. tMRCAs of selected clades within SRLV-B

\begin{tabular}{|c|c|c|c|c|c|c|c|c|}
\hline Partition & Node \# & Clade description & Posterior & Region(s) & Location & Loc $P$ & Age & 95\% HPD \\
\hline Gag MSA 1 & 1 & Thailand-Poland & 1.0 & C. Europe / S.E. Asia & Thailand & 0.77 & 1993 & $10-33$ \\
\hline Gag MSA 1 & 2 & Spanish & 1.0 & W. Europe & Spain & 0.97 & 1992 & $13-29$ \\
\hline Gag MSA 1 & 3 & Italian & 0.84 & W. Europe & Italy & 0.94 & 1990 & $11-36$ \\
\hline Gag MSA 1 & 4 & TH-PL-ES-IT & 0.75 & Europe / S.E. Asia & Italy & 0.71 & 1981 & $20-45$ \\
\hline Gag MSA 1 & 5 & Canada-China-Mexico & 0.62 & N. America & Canada & 0.71 & 1982 & $21-42$ \\
\hline Gag MSA 1 & 6 & Global & 0.84 & Global & Canada & 0.37 & 1978 & $25-42$ \\
\hline Gag MSA 1 & 7 & Root & 1.0 & Global & USA & 0.73 & 1972 & $37-54$ \\
\hline Gag MSA 2 & 1 & Slovenia-Italy & 0.83 & S. Europe & Switzerland & 0.79 & 1888 & $51-206$ \\
\hline Gag MSA 2 & 2 & Brazil & 1.0 & S. America & Brazil & 1.0 & 1974 & $19-60$ \\
\hline Gag MSA 2 & 3 & Canada-Mexico & 0.92 & N. America & Canada & 1.0 & 1877 & $61-228$ \\
\hline Gag MSA 2 & 4 & USA-Canada-Mexico-CN & 0.85 & Global & Canada & 0.5 & 1856 & $70-263$ \\
\hline Gag MSA 2 & 5 & Switzerland-Italy & 0.83 & Europe & Switzerland & 1.0 & 1862 & $66-250$ \\
\hline Gag MSA 2 & 6 & Root & 1.0 & Global & Switzerland & 0.92 & 1825 & $82-322$ \\
\hline Pol MSA 1 & 1 & Italy-Switzerland & 1.0 & C. Europe & Switzerland & 0.98 & 1986 & $16-34$ \\
\hline Pol MSA 1 & 2 & Slovenia & 1.0 & S. Europe & Slovenia & 1.0 & 2001 & $6-12$ \\
\hline Pol MSA 1 & 3 & Italy-Switzerland & 0.96 & Europe & Switzerland & 1.0 & 1966 & $25-47$ \\
\hline Pol MSA 1 & 4 & Root & 1.0 & Global & Switzerland & 0.63 & 1973 & $37-53$ \\
\hline Pol MSA 2 & 1 & Slovenia & 1.0 & S. Europe & Slovenia & 1.0 & 1989 & $11-35$ \\
\hline Pol MSA 2 & 2 & Switzerland-Slovenia & 0.89 & Europe & Switzerland & 1.0 & 1963 & $35-61$ \\
\hline Pol MSA 2 & 3 & China-US-Switzerland & 0.89 & Global & Switzerland & 1.0 & 1960 & $44-59$ \\
\hline Pol MSA 2 & 4 & Root & 1.0 & C. Europe & Switzerland & 1.0 & 1952 & $47-72$ \\
\hline
\end{tabular}

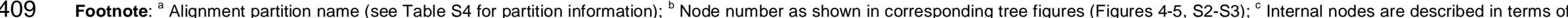

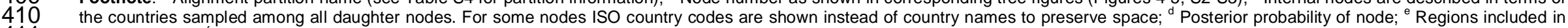
411 daughter nodes; ${ }^{\mathrm{T}}$ Estimated country location of node; ${ }^{9}$ Posterior probability of location. 


\section{$414 \quad$ Figure Legends}

415 Figure 1. Sampling in the Fertile Crescent region. The map in panel (a) indicates the 416 'Fertile Crescent' region in pink. The overlapping square indicates the location of the area 417 shown in panel (b), which includes the countries sampled in this study. Yellow circles 418 indicate sites in Lebanon where sampling was performed in this study; $A=$ Northern Lebanon 419 (Qornet el Sawda, Arez); B= Beqaa Valley. Beqaa Valley comprised three sites; North 420 (Aammiq), West (Swairi, Manara, Rashaya); Eastern (Nahle, Maqne, Knaisse). Pink circles 421 indicate sites previously sampled in Jordan: C=Northern Jordan; D=Jordan Valley.

Figure 2. Maximum likelihood (ML) phylogeny of 219 SRLV sequences based on capsid (CA) gene nucleotide sequences. The tree is midpoint rooted, and has been split across two panels. Taxa labels include isolate details separated by underscores as follows; accession number/isolate; species (Ovis=Ovis aries; Capra=Capra hircus); country of sampling (ISO two-letter country code); year of sampling. Circles next to taxa names indicate complete genome sequences, strain is shown in bold for these isolates. Brackets on the right indicate clades with bootstrap support that either derive from a single country or geographic region, or that have previously been assigned genotype subgroup status. For these clades, text associated with each bracket indicated whether the clade has been found in sheep only, goats only, or both sheep and goats (mixed). Inverted commas indicate that subgroup status is based on analysis of sub-genomic sequences. Asterisks indicate nodes with ML bootstrap support $>85 \%$, based on 100 bootstrap replicates. The scale bar indicates evolutionary distance in substitutions per site. outbreaks of disease associated with SRLV infection are indicated (see key), as recorded in Table S2.

443 Panel (a) shows analysis of an MSA partition in reverse transcriptase (RT), panel (b) shows 444 analysis of an MSA partition in integrase (IN). The scale bar indicates year dates. The key to 445 the upper left shows colour codes for the predicted country location of each node. Nodes for 446 which a country estimate could not be derived with posterior probabilities $<0.5$ are coloured 447 black. Error bars illustrating mean coalescence time estimates with $95 \%$ highest posterior density (HPD) are shown on internal nodes. 
450 Figure 5. Time-calibrated maximum likelihood Bayesian phylogenies of SRLV-B1.

451 Panel (a) shows analysis of an MSA partition in reverse transcriptase (RT), panel (b) shows

452 analysis of an MSA partition in integrase (IN). The scale bar indicates year dates. The key to 453 the upper left shows colour codes for the predicted country location of each node. Nodes for 454 which a country estimate could not be derived with posterior probabilities $<0.5$ are coloured 455 black. Error bars illustrating mean coalescence time estimates with 95\% highest posterior 456 density (HPD) are shown on internal nodes.

457

458 


\section{Acknowledgements}

RJG was supported by a grant from the UK Medical Research Council (No. MC_UU_12014/10). We thank Elie Barbour for contributing materials, lab space and equipment at the University of Beirut, Francesco Tolari for providing Jordanian sheep and goat blood samples, and Roman Biek, Pablo Murcia, Massimo Palmarini and Tiago Saraiva for useful discussions. We also thank Valgerður Andrésdóttir, Katerina Angelopoulou, Beatriz Amorena, Barbara Blacklaws, Miguel Fevereiro, Gordon Harkiss, Isidro Hötzel, Jinhai Huang, Britt Gjerset, Donald P. Knowles, Caroline Leroux, Bandit Nuansirchay, Keisuke Oguma, Monica Olech, Ramsés Reina, Sergio Rosati, Jörg Schüpbach, Hiroshi Sentsui, Hyun-Jin Shin, and Stephen Valas for providing SRLV sequence information.

\section{Uncategorized References}

1. Thormar H. 2005. Maedi-visna virus and its relationship to human immunodeficiency virus. AIDS reviews 7:233-245.

2. Sigurdsson B, Palsson PA. 1958. Visna of sheep; a slow, demyelinating infection. British journal of experimental pathology 39:519-528.

3. Sigurdsson B, Thormar H, Pálsson PA. 1960. Cultivation of visna virus in tissue culture. . Arch Gesamte Virusforsch 10:328.

4. Gudnadottir M, Palsson PA. 1967. Transmission of maedi by inoculation of a virus grown in tissue culture from maedi-affected lungs. The Journal of infectious diseases 117:1-6.

5. Crawford TB, Adams DS, Cheevers WP, Cork LC. 1980. Chronic arthritis in goats caused by a retrovirus. Science 207:997-999.

6. Shah C, Boni J, Huder JB, Vogt HR, Muhlherr J, Zanoni R, Miserez R, Lutz H, Schupbach J. 2004. Phylogenetic analysis and reclassification of caprine and ovine lentiviruses based on 104 new isolates: evidence for regular sheep-to-goat transmission and worldwide propagation through livestock trade. Virology 319:12-26.

7. Shah C, Huder JB, Boni J, Schonmann M, Muhlherr J, Lutz H, Schupbach J. 2004. Direct evidence for natural transmission of small-ruminant lentiviruses of subtype A4 from goats to sheep and vice versa. Journal of virology 78:7518-7522.

8. Grego E, Bertolotti L, Quasso A, Profiti M, Lacerenza D, Muz D, Rosati S. 2007. Genetic characterization of small ruminant lentivirus in Italian mixed flocks: evidence for a novel genotype circulating in a local goat population. The Journal of general virology 88:3423-3427.

9. Leroux C, Cruz JC, Mornex JF. 2010. SRLVs: a genetic continuum of lentiviral species in sheep and goats with cumulative evidence of cross species transmission. Current HIV research 8:94-100.

10. Bertolotti L, Mazzei M, Puggioni G, Carrozza ML, Dei Giudici S, Muz D, Juganaru M, Patta C, Tolari F, Rosati S. 2011. Characterization of new small ruminant lentivirus subtype B3 suggests animal trade within the Mediterranean Basin. The Journal of general virology 92:1923-1929.

11. Giammarioli M, Bazzucchi M, Puggioni G, Brajon G, Dei Giudici S, Taccori F, Feliziani F, De Mia GM. 2011. Phylogenetic analysis of small ruminant lentivirus (SRLV) in Italian flocks reveals the existence of novel genetic subtypes. Virus genes 43:380-384.

12. Reina R, Grego E, Profiti M, Glaria I, Robino P, Quasso A, Amorena B, Rosati S. 2009. Development of specific diagnostic test for small ruminant lentivirus genotype E. Veterinary microbiology 138:251-257.

13. Tolari F, Al-Ramadneh W, Mazzei M, Carrozza ML, Forzan M, Bandecchi P, Grego E, Rosati S. 2013. Small ruminant lentiviruses in Jordan: evaluation of sheep and goat serological response using recombinant and peptide antigens. Tropical animal health and production 45:1335-1340.

14. Edgar RC. 2004. MUSCLE: multiple sequence alignment with high accuracy and high throughput. Nucleic Acids Res 32:1792-1797. 
513 15. Suyama M, Torrents D, Bork P. 2006. PAL2NAL: robust conversion of protein sequence alignments into the corresponding codon alignments. Nucleic Acids Res 34:W609-612.

16. Singer JB, Thomson EC, McLauchlan J, Hughes J, Gifford RJ. 2018. GLUE: A flexible software system for virus sequence data. bioRxiv doi:10.1101/269274.

17. Stamatakis A. 2006. RAxML-VI-HPC: maximum likelihood-based phylogenetic analyses with thousands of taxa and mixed models. Bioinformatics 22:2688-2690.

18. Lemey P, Rambaut A, Drummond AJ, Suchard MA. 2009. Bayesian phylogeography finds its roots. PLoS Comput Biol 5:e1000520.

19. Zeder MA. 2008. Domestication and early agriculture in the Mediterranean Basin: Origins, diffusion, and impact. Proceedings of the National Academy of Sciences of the United States of America 105:11597-11604.

20. Gjerset B, Storset AK, Rimstad E. 2006. Genetic diversity of small-ruminant lentiviruses: characterization of Norwegian isolates of Caprine arthritis encephalitis virus. The Journal of general virology 87:573-580.

21. Grego E, Lacerenza D, Arias RR, Profiti M, Rosati S. 2009. Serological characterization of the new genotype $E$ of small ruminant lentivirus in Roccaverano goat flocks. Veterinary research communications 33 Suppl 1:137-140.

22. Bar-Yosef O. 1998. The Natufian culture in the Levant, threshold to the origins of agriculture. Evolutionary Anthropology 6:159-177.

23. Adams DS, Oliver RE, Ameghino E, DeMartini JC, Verwoerd DW, Houwers DJ, Waghela S, Gorham JR, Hyllseth B, Dawson M, et al. 1984. Global survey of serological evidence of caprine arthritis-encephalitis virus infection. The Veterinary record 115:493-495.

24. Sasani F, Javanbakht J, Hemmatzadeh F, Rajabi-Moghadam M, Aghamohammad Hassan M. 2013. Evaluation of histopathological on maedi disease with serological confirmation in North-East of Iran. Research Journal of Infectious Diseases 1.

25. Houwers DJ. 1990. Economic Importance, Epidemiology and Control, p 83-117. In Pétursson G, Hoff-Jørgensen R (ed), Maedi-Visna and Related Diseases, vol 10. Springer US.

26. MacDiarmid SC. 1983. Survey suggests low prevalence of caprine arthritis encephalitis. Surveillance 10:4-8.

27. Smith NH, Hewinson RG, Kremer K, Brosch R, Gordon SV. 2009. Myths and misconceptions: the origin and evolution of Mycobacterium tuberculosis. Nat Rev Microbiol 7:537-544.

28. Capomaccio S, Cappelli K, Cook RF, Nardi F, Gifford R, Marenzoni ML, Passamonti F. 2012. Geographic structuring of global EIAV isolates: a single origin for New World strains? Virus research 163:656-659.

29. Thormar H. 2013. The origin of lentivirus research: Maedi-visna virus. Curr HIV Res 11:2-9.

30. Ryder ML. 1983. Sheep and Man. Gerald Duckworh \& Co. Ltd, London.

31. Rocha J, Chen S Fau - Beja-Pereira A, Beja-Pereira A. 2011. Molecular evidence for fat-tailed sheep domestication.

32. Saraiva T. 2013. The Production and Circulation of Standardized Karakul Sheep and Frontier Settlement in the Empires of Hitler, Mussolini, and Salazar, p 135-150. In Jørgensen D, Jørgensen FA, Pritchard SB (ed), New Natures. University of Pittsburgh Press, Pittsburgh.

33. Young CC. 1914. Origin of Karakul Sheep. Journal of Heredity 5:445-446.

34. Rogers AL. 1981. Saanen Roots: A History of the Saanen Dairy Goat Breed in the United States. Dairy Goat Journal Publishing Company.

35. Cork LC, Hadlow WJ, Crawford TB, Gorham JR, Piper RC. 1974. Infectious leukoencephalomyelitis of young goats. The Journal of infectious diseases 129:134141. 
567 36. Apetrei C, Gaufin T, Gautam R, Vinton C, Hirsch V, Lewis M, Brenchley J,

568

569

570

571

572

573

574

575

576

577

578

579

580

581

582

583

584

585

586

587

588

589

590

591

592

593

594

595

596

597

598

599

600

601

602

603

604

605

606

607

608

609

610

611

612

613

614

615

616

617

618

619

620

621
Pandrea I. 2010. Pattern of SIVagm infection in patas monkeys suggests that host adaptation to simian immunodeficiency virus infection may result in resistance to infection and virus extinction. J Infect Dis 202 Suppl 3:S371-376.

37. Reina R, Grego E, Bertolotti L, De Meneghi D, Rosati S. 2009. Genome analysis of small-ruminant lentivirus genotype $\mathrm{E}$ : a caprine lentivirus with natural deletions of the dUTPase subunit, vpr-like accessory gene, and 70-base-pair repeat of the U3 region. J Virol 83:1152-1155.

38. Schmid A. 1934. Breeding of Farm Animals and Domestic Breeds in Switzerland. . Frauenfeld and Leipzig : Huber \&Co.

39. Reina R, Berriatua E, Lujan L, Juste R, Sanchez A, de Andres D, Amorena B. 2009. Prevention strategies against small ruminant lentiviruses: an update. Veterinary journal 182:31-37.

40. Park JE, Son SY, Shin HJ. 2010. Sequence comparison on gag gene of caprine arthritis encephalitis virus from Korea. Virus Genes 41:99-101.

41. Oguma K, Tanaka C, Harasawa R, Kimura A, Sasaki J, Goryo M, Sentsui H. 2013. Isolation of Maedi/visna Virus from a Sheep in Japan. The Journal of veterinary medical science / the Japanese Society of Veterinary Science doi:DN/JST.JSTAGE/jvms/13-0269 [pii].

42. Gifford RJ. 2012. Viral evolution in deep time: lentiviruses and mammals. Trends Genet 28:89-100.

43. Ravazzolo AP, Reischak D, Peterhans E, Zanoni R. 2001. Phylogenetic analysis of small ruminant lentiviruses from Southern Brazil. Virus research 79:117-123.

44. L'Homme Y, Ouardani M, Levesque V, Bertoni G, Simard C, Pisoni G. 2011. Molecular characterization and phylogenetic analysis of small ruminant lentiviruses isolated from Canadian sheep and goats. Virology journal 8:271.

45. Ramirez H, Glaria I, de Andres X, Martinez HA, Hernandez MM, Reina R, Iraizoz E, Crespo H, Berriatua E, Vazquez J, Amorena B, de Andres D. 2011. Recombinant small ruminant lentivirus subtype B1 in goats and sheep of imported breeds in Mexico. Veterinary journal 190:169-172.

46. Chiu IM, Yaniv A, Dahlberg JE, Gazit A, Skuntz SF, Tronick SR, Aaronson SA. 1985. Nucleotide sequence evidence for relationship of AIDS retrovirus to lentiviruses. Nature 317:366-368.

47. Saltarelli M, Querat G, Konings DA, Vigne R, Clements JE. 1990. Nucleotide sequence and transcriptional analysis of molecular clones of CAEV which generate infectious virus. Virology 179:347-364.

48. Cork LC, Hadlow WJ, Gorham JR, Piper RC, Crawford TB. 1974. Pathology of viral leukoencephalomyelitis of goats. Acta neuropathologica 29:281-292.

49. Herrmann-Hoesing LM, Broughton-Neiswanger LE, Gouine KC, White SN, Mousel MR, Lewis GS, Marshall KL, Knowles DP. 2010. Evaluation of a caprine arthritis-encephalitis virus/maedi-visna virus indirect enzyme-linked immunosorbent assay in the serological diagnosis of ovine progressive pneumonia virus in U.S. sheep. Clinical and vaccine immunology : CVI 17:307-310.

50. Herrmann LM, Hotzel I, Cheevers WP, On Top KP, Lewis GS, Knowles DP. 2004. Seven new ovine progressive pneumonia virus (OPPV) field isolates from Dubois Idaho sheep comprise part of OPPV clade II based on surface envelope glycoprotein (SU) sequences. Virus research 102:215-220.

51. Knowles DP, Jr., Cheevers WP, McGuire TC, Brassfield AL, Harwood WG, Stem TA. 1991. Structure and genetic variability of envelope glycoproteins of two antigenic variants of caprine arthritis-encephalitis lentivirus. Journal of virology 65:5744-5750.

52. Kennedy RC, Eklund CM, Lopez C, Hadlow WJ. 1968. Isolation of a virus from the lungs of Montana sheep affected with progressive pneumonia. Virology 35:483-484.

53. Karr BM, Chebloune Y, Leung K, Narayan O. 1996. Genetic characterization of two phenotypically distinct North American ovine lentiviruses and their possible origin from caprine arthritis-encephalitis virus. Virology 225:1-10. 
622 54. Querat G, Audoly G, Sonigo P, Vigne R. 1990. Nucleotide sequence analysis of

623

624

625

626

627

628

629

630

631

632

633

634

635

636

637

638

639

640

641

642

643

644

645

646

647

648

649

650

651

652

653

654

655

656

657

658

659

660

661

662

663

664

665

666

667

668

669

670

671

672

673

674

675

676 SA-OMVV, a visna-related ovine lentivirus: phylogenetic history of lentiviruses. Virology 175:434-447.

55. Huang J, Sun Y, Liu Y, Xiao H, Zhuang S. 2012. Development of a loop-mediated isothermal amplification method for rapid detection of caprine arthritis-encephalitis virus proviral DNA. Archives of virology 157:1463-1469.

56. Juan-juan Q, Wei G, Li-ping Z, Rong-xian S, Wen-hua X. 2005. The Gene Cloning and Sequence Analysis of the Whole Genome of Caprine Arthritis Encephalitis Virus(CAEV)-GANSU Strain Chinese Journal of Virology 5.

57. Muz D, Oguzoglu TC, Rosati S, Reina R, Bertolotti L, Burgu I. 2012. First molecular characterization of visna/maedi viruses from naturally infected sheep in Turkey. Archives of virology 158:559-570.

58. Ramirez H, Reina R, Bertolotti L, Cenoz A, Hernandez MM, San Roman B, Glaria I, de Andres X, Crespo H, Jauregui P, Benavides J, Polledo L, Perez V, GarciaMarin JF, Rosati S, Amorena B, de Andres D. 2012. Study of compartmentalization in the visna clinical form of small ruminant lentivirus infection in sheep. BMC veterinary research 8:8.

59. de Andres X, Ramirez H, Bertolotti L, San Roman B, Glaria I, Crespo H, Jauregui P, Minguijon E, Juste R, Leginagoikoa I, Perez M, Lujan L, Badiola JJ, Polledo L, Garcia-Marin JF, Riezu JI, Borras-Cuesta F, de Andres D, Rosati S, Reina R, Amorena B. 2013. An insight into a combination of ELISA strategies to diagnose small ruminant lentivirus infections. Veterinary immunology and immunopathology 152:277-288.

60. Reina R, Mora MI, Glaria I, Garcia I, Solano C, Lujan L, Badiola JJ, Contreras A, Berriatua E, Juste R, Mamoun RZ, Rolland M, Amorena B, de Andres D. 2006. Molecular characterization and phylogenetic study of Maedi Visna and Caprine Arthritis Encephalitis viral sequences in sheep and goats from Spain. Virus research 121:189-198.

61. Glaria I, Reina R, Crespo H, de Andres X, Ramirez H, Biescas E, Perez MM, Badiola J, Lujan L, Amorena B, de Andres D. 2009. Phylogenetic analysis of SRLV sequences from an arthritic sheep outbreak demonstrates the introduction of CAEVlike viruses among Spanish sheep. Veterinary microbiology 138:156-162.

62. Glaria I, Reina R, Ramirez H, de Andres X, Crespo H, Jauregui P, Salazar E, Lujan L, Perez MM, Benavides J, Perez V, Polledo L, Garcia-Marin JF, Riezu JI, Borras F, Amorena B, de Andres D. 2012. Visna/Maedi virus genetic characterization and serological diagnosis of infection in sheep from a neurological outbreak. Veterinary microbiology 155:137-146.

63. Barros SC, Ramos F, Duarte M, Fagulha T, Cruz B, Fevereiro M. 2004. Genomic characterization of a slow/low maedi visna virus. Virus genes 29:199-210.

64. Laamanen I, Jakava-Viljanen M, Sihvonen L. 2007. Genetic characterization of maedi-visna virus (MVV) detected in Finland. Veterinary microbiology 122:357-365.

65. Leroux C, Chastang J, Greenland T, Mornex JF. 1997. Genomic heterogeneity of small ruminant lentiviruses: existence of heterogeneous populations in sheep and of the same lentiviral genotypes in sheep and goats. Archives of virology 142:11251137.

66. Germain K, Valas S. 2006. Distribution and heterogeneity of small ruminant lentivirus envelope subtypes in naturally infected French sheep. Virus research 120:156-162.

67. Valas S, Benoit C, Baudry C, Perrin G, Mamoun RZ. 2000. Variability and immunogenicity of caprine arthritis-encephalitis virus surface glycoprotein. Journal of virology 74:6178-6185.

68. Valas S, Benoit C, Guionaud C, Perrin G, Mamoun RZ. 1997. North American and French caprine arthritis-encephalitis viruses emerge from ovine maedi-visna viruses. Virology 237:307-318.

69. Andresdottir V, Tang X, Agnarsdottir G, Andresson OS, Georgsson G, Skraban R, Torsteinsdottir S, Rafnar B, Benediktsdottir E, Matthiasdottir S, Arnadottir S, 
Hognadottir S, Palsson PA, Petursson G. 1998. Biological and genetic differences between lung- and brain-derived isolates of maedi-visna virus. Virus genes 16:281293.

70. Sigurdsson B, Grimsson H, Palsson PA. 1952. Maedi, a chronic, progressive infection of sheep's lungs. The Journal of infectious diseases 90:233-241.

71. Braun MJ, Clements JE, Gonda MA. 1987. The visna virus genome: evidence for a hypervariable site in the env gene and sequence homology among lentivirus envelope proteins. Journal of virology 61:4046-4054.

72. Gjerset B, Jonassen CM, Rimstad E. 2007. Natural transmission and comparative analysis of small ruminant lentiviruses in the Norwegian sheep and goat populations. Virus research 125:153-161.

73. Sargan DR, Bennet ID, Cousens C, Roy DJ, Blacklaws BA, Dalziel RG, Watt NJ, McConnell I. 1991. Nucleotide sequence of EV1, a British isolate of maedi-visna virus. The Journal of general virology 72 ( Pt 8):1893-1903.

74. Angelopoulou K, Karanikolaou K, Papanastasopoulou M, Koumpati-Artopiou M, Vlemmas I, Papadopoulos O, Koptopoulos G. 2005. First partial characterisation of small ruminant lentiviruses from Greece. Veterinary microbiology 109:1-9.

75. Pisoni G, Bertoni G, Manarolla G, Vogt HR, Scaccabarozzi L, Locatelli C, Moroni P. 2010. Genetic analysis of small ruminant lentiviruses following lactogenic transmission. Virology 407:91-99.

76. Pisoni G, Moroni P, Turin L, Bertoni G. 2007. Compartmentalization of small ruminant lentivirus between blood and colostrum in infected goats. Virology 369:119130.

77. Pisoni G, Bertoni G, Puricelli M, Maccalli M, Moroni P. 2007. Demonstration of coinfection with and recombination by caprine arthritis-encephalitis virus and maedivisna virus in naturally infected goats. Journal of virology 81:4948-4955.

78. Pisoni G, Quasso A, Moroni P. 2005. Phylogenetic analysis of small-ruminant lentivirus subtype B1 in mixed flocks: evidence for natural transmission from goats to sheep. Virology 339:147-152.

79. Grego E, Profiti M, Giammarioli M, Giannino L, Rutili D, Woodall C, Rosati S. 2002. Genetic heterogeneity of small ruminant lentiviruses involves immunodominant epitope of capsid antigen and affects sensitivity of single-strain-based immunoassay. Clinical and diagnostic laboratory immunology 9:828-832.

80. Reina R, Bertolotti L, Dei Giudici S, Puggioni G, Ponti N, Profiti M, Patta C, Rosati S. 2010. Small ruminant lentivirus genotype $E$ is widespread in Sarda goat. Veterinary microbiology 144:24-31.

81. Carrozza ML, Mazzei M, Lacerenza D, Del Chiaro L, Giammarioli M, Marini C, Rutili D, Rosati S, Tolari F. 2009. Seroconversion against SU5 derived synthetic peptides in sheep experimentally infected with different SRLV genotypes. Veterinary microbiology 137:369-374.

82. Olech M, Rachid A, Croise B, Kuzmak J, Valas S. 2012. Genetic and antigenic characterization of small ruminant lentiviruses circulating in Poland. Virus research 163:528-536.

83. Kuhar U, Barlic-Maganja D, Grom J. 2012. Phylogenetic analysis of small ruminant lentiviruses detected in Slovenia. Veterinary microbiology 162:201-206. 

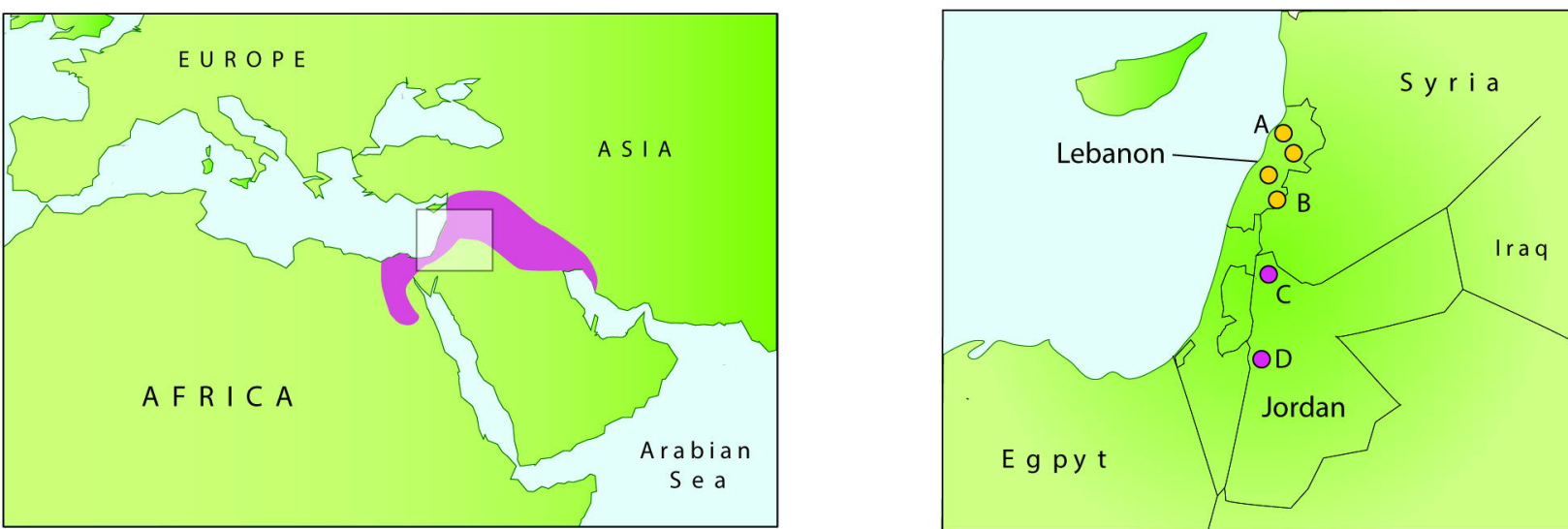


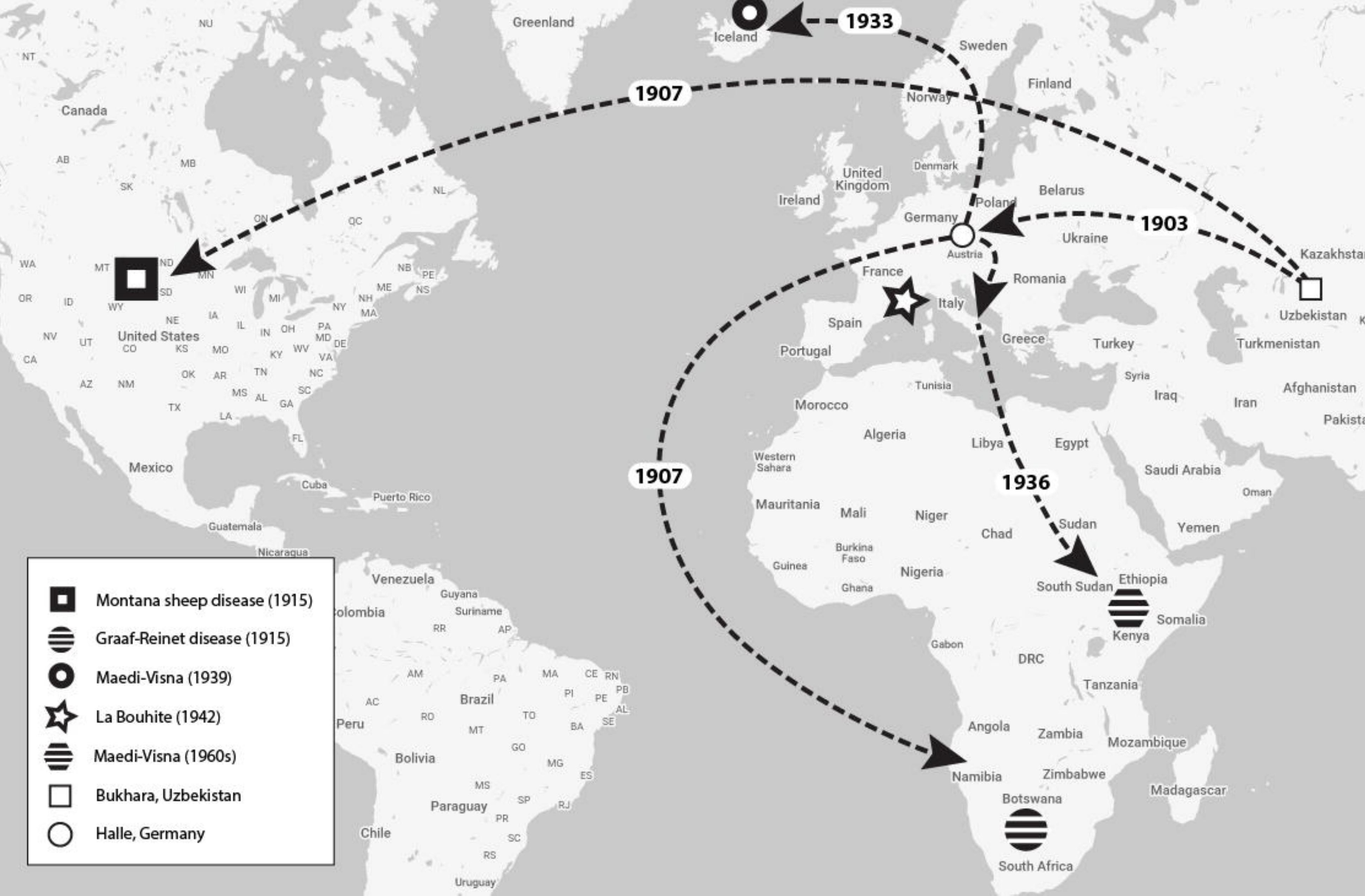



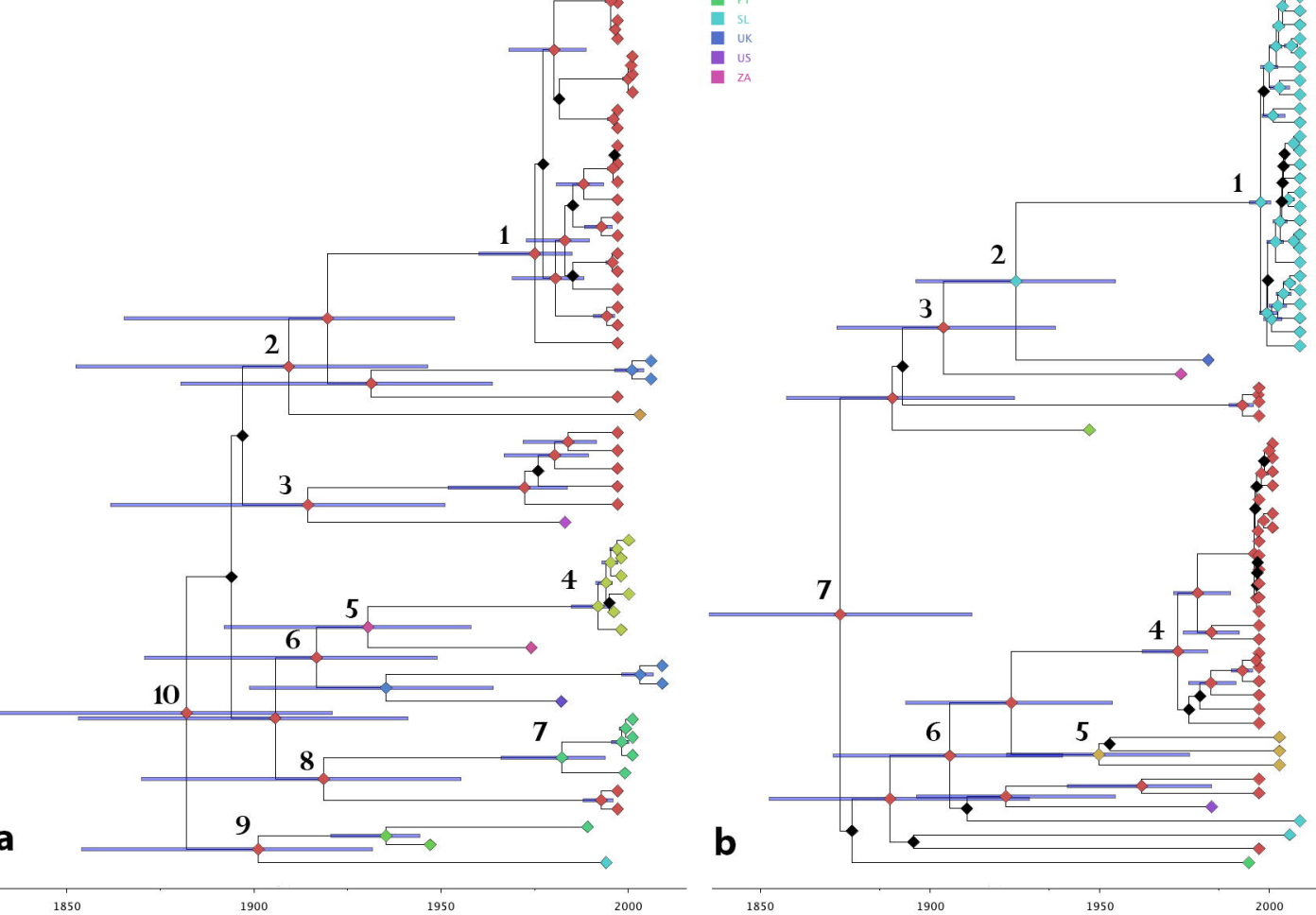
